\title{
Eco and Peirce on Abduction
}

\section{Francesco Bellucci}

\section{(2) OpenEdition \\ Journals}

Electronic version

URL: http://journals.openedition.org/ejpap/1122

DOI: 10.4000/ejpap.1122

ISSN: 2036-4091

\section{Publisher}

Associazione Pragma

\section{Electronic reference}

Francesco Bellucci, «Eco and Peirce on Abduction », European Journal of Pragmatism and American Philosophy [Online], X-1 | 2018, Online since 20 July 2018, connection on 19 April 2019. URL : http:// journals.openedition.org/ejpap/1122 ; DOI : 10.4000/ejpap.1122

This text was automatically generated on 19 April 2019

Licence Creative Commons

Author retains copyright and grants the European Journal of Pragmatism and American Philosophy right of first publication with the work simultaneously licensed under a Creative Commons AttributionNonCommercial-NoDerivatives 4.0 International License. 


\title{
Eco and Peirce on Abduction
}

\author{
Francesco Bellucci
}

1 One of the key concepts that Eco took from Peirce is that of "abduction," or reasoning to an explanatory hypothesis. This concept is central to his foundation of a semiotic or interpretative semantics, one of whose component is a theory of inference, and especially of abductive inference. Though there is probably only one "official" place where Eco expounds his theory of abductive reasoning - the article "Horns, Hooves, and Insteps" in The Sign of Three - yet Eco's theory is spanned over tens of papers and books, including his fictional books.

2 Eco's fictional books have often been considered as, to say the least, "profoundly connected" with his scholarly work. But Paolucci has persuasively argued that not only Eco's philosophical work influenced his fictional work, but also, and more crucially, that his fictional works are an integral part of his philosophy: "[t]he union of the theoretical and nontheoretical works constitute Eco's philosophical legacy, his 'philosophy'." (Paolucci 2017a: 254). Moving from this assumption, this paper seeks to explore Eco's philosophy of abduction moving from both his theoretical and his non-theoretical works, these two sides forming in fact an inextricable unity.

3 The Name of the Rose contains one of the best and most detailed accounts of Eco's philosophy of abductive reasoning. Among the several abductions that the two main characters, William of Baskerville and Adso of Melk, perform in the course of the story, the abduction concerning the horse Brunellus in the overture of the book is certainly the most remarkable, if only because it is commented at length in the sequel of the book. The model of the Brunellus episode is to be found in the third chapter of Voltaire's Zadig, in which Zadig abduces some of the features of the king's horse that the royal officials are seeking. ${ }^{1}$ The Zadig episode is analyzed by Eco in "Horns," where a typology of abductions is presented.

4 Eco took his notion of abductive inference from Peirce. Peirce's mature (i.e., post-1900) theory of abduction comprises both an analysis of the abductive process of reasoning within the larger horizon of scientific inquiry, and a philosophical justification of this kind of reasoning. Both these aspects are present in Eco's theory of abduction, and both are represented in the analysis of the Zadig episode offered in "Horns." However, I shall 
argue, a "more Peircean" analysis of abductive reasoning than that given in "Horns" about Zadig is contained in the Brunellus episode in The Name of the Rose, because there Eco reproduces more accurately than he does with Zadig the Peircean model of scientific inquiry. As I will try to show, while Zadig's horse abduction seems to be fashioned on Peirce's early analysis of abduction (the data are signs, and particularly indices that form an icon, of the conclusion), William's course of reasoning is more akin to Peirce's mature analysis of abduction (a hypothesis is suggested by abduction from data as signs, and is subsequently explicated by deduction and verified by induction). The overture of Eco's most famous novel is consequently a crucial component of Eco's theory of abductive reasoning. Also, I will argue that, like Peirce, Eco solved the problem of the justification of abduction through the idea that this justification is itself abductive (meta-abduction in Eco, ur-abduction in Peirce).

The paper is organized as follows. The first section expounds the essentials of Peirce's theory of abduction, and explains how Peirce moved from seeing abduction as a kind of reasoning (in his earliest writings) to seeing it as a stage of the larger process of inquiry (in his mature writings). The second section deals with the Brunellus abduction, and shows that, just like in Peirce's three-stages model of inquiry, William's abductions are explicated by deduction and verified by induction. The third section examines the problem of the justification of abductive reasoning (especially, but not exclusively, as discussed in "Horns").

\section{A Sketch of Abductive Logic}

6 In his earliest writings on the three forms of inference (1865-1867) Peirce had explained abduction (at that time called "hypothesis") as an argument in which the premises are an icon of the conclusion. More precisely, abduction is the transformation of a conjunctive term (which, like an icon, has connotation but lacks appropriate denotation, W1: 279) into a symbol on the principle that "the symbol which embodies any form [conjunctive term] is predicable of the same subjects as the form itself" (W1: 188), or in other words that any symbol that possesses any character also possessed by an object is itself a symbol of the object. As he explains in the 1867 "Classification" (interpolation in brackets mine): abduction is "an argument which assumes that a term [symbol] which necessarily involves a certain number of characters [conjunctive term, icon] [...] may be predicated of any object [object] which has all these characters" (W2: 48). The substance of this doctrine, variously rephrased, can be found in the "New List" (1867, W2: 58), in "Some Consequences of Four Incapacities" (1868, W2: 217-8), and in "Deduction, Induction, and Hypothesis" (1878, W3: 326-7). The maturest version of this early theory is in the article "A Theory of Probable Inference" in the volume of Studies in Logic edited by Peirce himself in 1883, where Peirce explains induction and abduction as inversions of a valid deductive syllogism (W4: $416-23){ }^{2}$

7 Later in his life Peirce came to see that his early view of abduction was incorrect. In July 1910 he writes to Paul Carus that "the division of the elementary kinds of reasoning into three heads was made by me in my first lectures and was published in 1869 in Harris's Journal of Speculative Philosophy. I still consider that it had a sound basis. Only in almost everything I printed before the beginning of this century [...] I more or less mixed up Hypothesis and Induction." (RL 77: 226-7 = CP 8.227). In the sketch of logical critics given in the Minute Logic Peirce says: 
Upon this subject [i.e. abduction], my doctrine has been immensely improved since my essay "On The Theory of Probable Inference" was published in 1883. In what I there said about "Hypothetic Inference" I was an explorer upon untrodden ground. I committed, though I half corrected, a slight positive error, which is easily set right without essentially altering my position. But my capital error was a negative one, in not perceiving that, according to my own principles, the reasoning with which I was there dealing could not be the reasoning by which we are led to adopt a hypothesis, although I all but stated as much. But I was too much taken up in considering syllogistic forms and the doctrine of logical extension and comprehension, both of which I made more fundamental than they really are. As long as I held that opinion, my conceptions of Abduction necessarily confused two different kinds of reasoning. (CP 2.102)

The two different kinds of reasoning that Peirce had conflated under the conception of abduction are abduction proper, which he now describes as the process of forming an explanatory hypothesis, and qualitative induction, which is an induction about characters. He now realizes that what he used to call "hypothesis" and "abduction" in his earlier writings has not a substantially different leading principle from induction: an abduction in the sense of 1865-1883 is, at bottom, an induction about characters rather than about things. Instead of reasoning about things in extension (enumerative terms, indices), as in induction, we reason about characters in comprehension (conjunctive terms, icons): instead of saying that the characters possessed by the sample are possessed by the whole, we say that something which possesses a sample of the characters of a thing possesses all the characters of that thing (i.e., is that thing whose characters it possesses). This second form of reasoning is properly called abductive or qualitative induction. Its leading principle is inductive, however, not abductive. So in the second Cambridge Conference of 1898 on "Types of Reasoning" Peirce declares: "I first gave this theory in 1867, improving it slightly in 1868. In 1878 I gave a popular account of it in which I rightly insisted upon the radical distinction between Induction and Retroduction. In 1883, I made a careful restatement with considerable improvement. But I was led astray by trusting to the perfect balance of logical breadth and depth into the mistake of treating Retroduction as a kind of Induction." (R 441: 29-30). Both induction proper and the 1865-1883 form of reasoning called abduction are inferences from the sample to the whole. In the one the sample is taken in extension, in the other in comprehension. But all inference from the sample to the whole is essentially inductive. Abduction proper, also called "retroduction," is not an inference from the sample to the whole; it is, rather, the process of reasoning by which we form an explanatory hypothesis.

The fundamental change in Peirce's conception of abduction occurs in the decade that precedes the Minute Logic. ${ }^{3}$ In the 1901 article "On the Logic of Drawing History from Ancient Documents" (R 690 = EP2: 75-114) Peirce presents a view of the articulation of scientific discovery in which the three kinds of arguments occur as distinct stages of a typical scientific investigation. The first stage of inquiry is abduction. When we are confronted with facts contrary to our expectations, an explanation is called for: "the explanation must be such a proposition as would lead to the prediction of the observed facts, either as necessary consequences or at least as very probable under the circumstances. A hypothesis, then, has to be adopted, which is likely in itself, and renders the facts likely. This step of adopting a hypothesis as being suggested by the facts, is what I call abduction. I reckon it as a form of inference, however problematical the hypothesis may be held." (EP2: 94-5). The "classic" formulation of the logical form of abduction is in the seventh and last Harvard Lecture of 1903: 
The surprising fact, $\mathrm{C}$, is observed.

But if A were true, $C$ would be a matter of course.

Hence, there is reason to suspect that A is true. (EP2: $231=$ CP 5.189) hypothesis: "the first thing that will be done, as soon as a hypothesis has been adopted, will be to trace out its necessary and probable experiential consequences. This step is deduction." (EP2: 95). By abduction we form the hypothesis that "there is reason to suspect that A is true". By deduction we trace the necessary consequences of the hypothesis. These consequences are experimental predictions from the hypothesis, and are selected independently of whether or not they are known to be true. The requirement that the hypothesis be experimental is satisfied by following the pragmatic maxim: only those hypotheses are admissible which can be put to experimental test. Of course, the surprising fact which prompted the formation of the hypothesis in the first place " $\mathrm{C}$ " in the Harvard example) is one of necessary consequences of the hypothesis, for were it not, the hypothesis could not be said to explain the facts (to say that the surprising fact is one of the necessary consequences of the hypothesis is to say that its explanatory syllogism is a valid one). But besides the surprising fact, from the hypothesis several other necessary consequences can be drawn, and this is necessary if we are to test the hypothesis.

The third stage of inquiry consists in the testing of the hypothesis through a testing of those predictions:

Having, then, by means of deduction, drawn from a hypothesis predictions as to what the results of experiment will be, we proceed to test the hypothesis by making the experiments and comparing those predictions with the actual results of experiment. [...] [When] we find that prediction after prediction, notwithstanding a preference for putting the most unlikely ones to the test, is verified by experiment, whether without modification or with a merely quantitative modification, we begin to accord to the hypothesis a standing among scientific results. This sort of inference it is, from experiments testing predictions based on a hypothesis, that is alone properly entitled to be called induction. (EP2: 96-7; original emphasis)

The operation of testing a hypothesis by experiment is induction. It consists in considering the predictions from the hypothesis, remarking what conditions should be satisfied in order for those predictions to be fulfilled, causing those conditions to be satisfied by experiment, and noting the result of the experiment. If the predictions are fulfilled, the hypothesis is inductively given a certain confidence. As Peirce remarks, in a 1901 article on "Hume on Miracles," "it is not the fact predicted that in any degree necessitates the truth of the hypothesis or even renders it probable. It is the fact that it has been predicted successfully and that it is a haphazard specimen of all the predictions which might be based on the hypothesis." (CP 6.527). The inductive character of the procedure of hypothesis verification derives from the fact that the predictions tested are a sample of all the predictions from the same hypothesis that could be tested. ${ }^{4}$ In other words, the third step of inquiry is the inductive generalization that what is found true of some predictions would be found true of all of them.

Let us take Peirce's example of the ex-priest contained in one of the drafts of the Carnegie Application of 1902 (RL 75) in order to illustrate the three-stages process of inquiry: "Suppose, then, that, being seated in a street car, I remark a man opposite to me whose appearance and behavior unite characters which I am surprised to find together in the same person." (RL 75: 163-4). A certain surprising combination of characters, say characters $c_{1}, \ldots c_{n}$, are found in the man sitting in front of Peirce in the car. In order to 
reduce to some order this surprising fact (the occurrence of of $c_{1}, \ldots c_{n}$ ), i.e., in order to explain them, he makes the hypothesis that the man is an ex-priest. The reasoning by which he form this hypothesis is abduction, and has the following form:

This man possesses the characters $c_{1}, \ldots c_{n}$.

If he were an ex-priest, he would possess the characters $c_{1}, \ldots c_{n}$.

Therefore, there is reason to suspect that he is an ex-priest.

In order to test this hypothesis, Peirce has to draw from it predictions that can be tested empirically, at least in principle. Thus two further steps follow abduction in the process of scientific inquiry. The second step is deduction, and consists in drawing predictions (which are necessary, or deductive, consequences) from the hypothesis. For example, if the man is a priest, he should be tonsured:

This man is an ex-priest.

Ex-priest are tonsured.

Therefore, this man is tonsured.

This is deduction, and by deduction predictions are made. The prediction that the man will be found to be tonsured, which is a sample of all the necessary consequences of the hypothesis, has now to be put to test by induction. To test the prediction Peirce has to make an experiment: "I say something to him calculated to make him take off his hat. He does so, and I find that he is indeed tonsured." (Ibid.). Peirce can thus conclude that the man is an ex-priest on the basis of the induction that as this prediction is verified so must all the predictions drawn from the same hypothesis. In other words, the third step of inquiry is the inductive generalization that what is found true of a sample of the predictions will be found true of all of them. As Peirce writes in the Minute Logic, "induction is an argument which starts out from a hypothesis, resulting from a previous abduction, and from virtual predictions, drawn by deduction, of the results of possible experiments, concludes that the hypothesis is true, in the measure in which these predictions are verified" (CP 2.96).

In Peirce's mature view of the logic of scientific inquiry, the three forms of inference are not merely three distinct modes of reasoning each characterized by its own leading principle; also, each belongs to a different stage of scientific inquiry. As he would later write, "There are three kinds of reasoning based upon as many utterly distinct purposes and principles. They are severally used in the three logical stages of research." (R 756: 1 c. 1906). To signalize their double nature (both stages and kinds) in his later writings Peirce prefers to speak of "grades" (R 843, 1908), or even "orders" (R 752, 1914), rather than simply of "kinds" of reasoning.

17 We make abductions in order to explain surprising facts, but the "abductive moment" is only the first part of inquiry: "Retroduction does not afford security. The hypothesis must be tested." (CP 6.470). Abduction is for the sake of verification. Its conclusion does not say "A is true," but "there is reason to suspect that A is true," that is, "it is worth inquiring whether A is true." So Peirce writes to Lady Welby in 1905:

[The] "interrogative mood" does not mean the mere idle entertainment of an idea. It means that it will be wise to go to some expense, dependent upon the advantage that would accrue from knowing that Any/Some $\mathrm{S}$ is $\mathrm{M}$, provided that expense would render it safe to act on that assumption supposing it to be true. This is the kind of reasoning called reasoning from consequent to antecedent. [...] Instead of "interrogatory," the mood of the conclusion might more accurately be called "investigand," and be expressed as follows: It is to be inquired whether A is not 
true. The reasoning might be called "Reasoning from Surprise to Inquiry." (Peirce

to Welby, July 16, 1905, RL 463; original emphasis)

By abduction a hypothesis is suggested. The conclusion of abduction, which contains the hypothesis, is not in the indicative but in the interrogative mood: it advances the hypothesis not as true, nor as a mere idea, but as an idea worth investigating in order to determine its truth. Abduction is not an isolated form of reasoning, but is embedded within the larger horizon of inquiry, because a hypothesis is first put forth by abduction, and then verified by induction (through verification of its observable deductive consequences). Scientific inquiry is a "dialectic" between abduction and induction, which are the beginning and the end of hypothetical thinking, and which are connected by the gateway of deduction. ${ }^{5}$

\section{Brunellus and Other Horses}

According to Eco's analysis in "Horns," Zadig infers the features of the horse that the royal officials are seeking through imprints, symptoms and clues. ${ }^{6}$ Here is Zadig's own explanation:

With respect to the horse of the king of kings, you must know that as I was walking along the roads in that same wood, I perceived the marks of a horse's shoes, all at equal distances. "There," I said to myself, "went a horse with a faultless gallop." The dust upon the trees, where the width of the road was not more than seven feet, was here and there rubbed off on both sides, three feet and a half away from the middle of the road. "This horse," said I, "has a tail three feet and a half long, which, by its movements to right and left, has whisked away the dust." I saw, where the trees formed a canopy five feet above the ground, leaves lately fallen from the boughs; and I concluded that the horse had touched them, and was therefore five feet high. As to his bit, it must be of gold twenty-three carats fine, for he had rubbed its bosses against a touchstone, the properties of which I had ascertained. Lastly, I inferred from the marks that his shoes left upon stones of another kind, that he was shod with silver of eleven pennyweights in quality. (Voltaire 1910: 60)

The marks of the horse's shoes are imprints, but the fact that the imprints are all at equal distance is a sign (a clue) that the horse has a perfect gallop. The fact that the dust upon the trees is rubbed off on both sides at a distance of three feet and half from the middle of the road is a sign (a symptom) that the horse has a tail of that length. The leaves fallen from the boughs are a sign (a symptom) that the animal is five feet tall. The gold on the touchstone is a sign (a clue) that the horse has bosses of gold twenty-three carats. And finally, the silver on the pebbles is a sign (a clue) that the shoes of the horses are shod with silver of a certain quality. Collectively, these signs form an icon of a horse with certain characters. The signs themselves are indices (clues, symptoms, and imprints), but collectively they depict a horse, and are therefore the icon of a horse. According to the early Peirce, in abduction the premises are an icon of the conclusion.

The king's official asks Zadig whether he has seen the king's horse passing that way. As Eco observes, "Voltaire is not explicit on this point, but let us suppose that Zadig has turned over in his mind many alternative hypotheses and has definitely chosen the final one only when he has met the men of the Court looking for a horse" (1983: 213). When the official asks Zadig whether he has seen the king's horse, this becomes for Zadig the confirmation that his horse hypothesis was correct. Only at that point those signs become 
for him the icon of the king's horse. But Zadig does nothing in particular to put his hypothesis to test.

William of Baskerville's horse abduction is of the same type as Zadig's. But William's also features several further elements which deserve some commentary. While he and Adso are toiling up the path around the mountain that leads to the abbey, they see an "agitated band of monks and servants" (NR 22). When one of them, the abbey's cellarer Remigio of Varagine, introduces himself to the visitors, William says:

The horse came this way and took the path to the right. He will not get far, because he will have to stop when he reaches the dungheap. He is too intelligent to plunge down that precipitous slope [...] it is obvious you are hunting for Brunellus, the abbot's favorite horse, fifteen hands, the fastest in your stables, with a dark coat, a full tail, small round hoofs, but a very steady gait; small head, sharp ears, big eyes. He went to the right, as I said, but you should hurry, in any case. (NR 23)

And here is William's later explanation to Adso:

At the crossroads, on the still-fresh snow, a horse's hoofprints stood out very neatly, heading for the path to our left. Neatly spaced, those marks said that the hoof was small and round, and the gallop quite regular - and so I deduced the nature of the horse, and the fact that it was not running wildly like a crazed animal. At the point where the pines formed a natural roof, some twigs had been freshly broken off at a height of five feet. One of the blackberry bushes where the animal must have turned to take the path to his right, proudly switching his handsome tail, still held some long black horsehairs in its brambles. You will not say, finally, that you do not know that path leads to the dungheap, because as we passed the lower curve we saw the spill of waste down the sheer cliff below the great east tower, staining the snow; and from the situation of the crossroads, the path could only lead in that direction. (NR 24)

Unlike Zadig, for whom the officials' question is the confirmation that the hypothesis that he had formed upon the basis of indices that collectively form an icon is correct, for William the fact that the men appear "agitated" is a further sign that contributes to the formation of the Brunellus hypothesis. The appearance of the "agitated band" is for him a sign that they are seeking something. The imprints suggest William that a horse had passed that way, and their orientation is a sign (a clue) that the horse was heading to the right. The shape of the hoofs is a sign (a clue) of the "nature of the horse," while the distance between them is a sign (a clue) that the horse has a perfect gallop. The broken twigs are a sign (a symptom) that the animal is five feet tall. The color of the hairs that the horse left on the blackberry bushes is a sign (a symptom) that the horse is black. And the fact that the cellarer in person is part of the "agitated band" is a sign (a clue) that the horse is considered to be the finest of the abbey. Just like Zadig, who can infer the royal horse's appearance before apprehending that in fact the king's horse is sought, William can infer the horse's appearance before knowing what the men are after. But unlike Zadig, for whom the interrogation of the official is the verification of the horse hypothesis, William is prepared to offer his Brunellus hypothesis before being addressed by the monks.

However, William's reasoning differs from Zadig's under a more fundamental respect. The presence and the shape of the imprints, the hairs left on the bushes, and the broken twigs allow him to reconstruct some of the features of the horse. But the description that he offers to the cellarer cannot be explained only in terms of what he has actually seen. Hence, Adso's question: 
"Yes," I said, "but what about the small head, the sharp ears, the big eyes ...?" "I am not sure he has those features, but no doubt the monks firmly believe he does. As Isidore of Seville said, the beauty of a horse requires that the head be small, siccum prope pelle ossibus adhaerente, short and pointed ears, big eyes, flaring nostrils, erect neck, thick mane and tail, round and solid hoofs.' If the horse whose passing I inferred had not really been the finest of the stables, stableboys would have been out chasing him, but instead, the cellarer in person had undertaken the search. And a monk who considers a horse excellent, whatever his natural forms, can only see him as the auctoritates have described him, especially if" - and here he smiled slyly in my direction - "the describer is a learned Benedictine." (NR 24)

As we noticed, from the observed, surprising fact that the cellarer in person is taking part in the chase William infers that the horse is thought to be the finest of the abbey. We could express this piece of abductive inference in the Harvard scheme:

(I) The surprising fact that the cellarer himself is taking part in the chase for the horse is observed. But if the horse that has escaped were considered to be the finest of the abbey, the cellarer himself would take part in the chase.

Hence, there is reason to suspect that the horse is considered to be the finest of the abbey. William makes as to the characters of the horse: from the fact that the horse is the finest of the abbey (conclusion of I, premise of II) William infers that it should be believed by the monks to possess the characters (small head, sharp ears, and big eyes) that, according to the authority of Isidore of Seville, make of a horse a fine horse. What kind of inference is it and what is its logical form?

According to Bondanella, with (II) "William has clearly gone beyond the boundaries of any empirical investigation - he has begun to make broad hypothetical inferences rather than to deduce from logical premises [...] William has become a semiotician employing a method that is far closer to the abduction discussed by Peirce or Eco himself than to the logical deductions we associate with real-world detectives or a host of fictional investigators." (1997: 108). Bondanella is right that (II) is not the kind of inference usually employed by detectives. But he is wrong that the inference in question is abductive. For one thing, some confusion is caused by a terminological distortion. As variously observed (cf. Sebeok \& Sebeok 1983; Truzzi 1983), despite of Sherlock Holmes's classical exposition of the "Science of Deduction" in A Study in Scarlet (1887, I, 2), the kind of reasoning that Conan Doyle's detective typically employs is abductive, not deductive. As Holmes, William of Barskerville too speaks of deduction, ${ }^{7}$ but there is reason to suspect that in this case Eco is deliberately ignoring the Peircean distinction between deduction and abduction in order to more effectively suggest the inter-textual parallel with Holmes' "deductions" (which are actually abductions). And we have seen that William's inference from the signs found on the path to the features of the horse sought by the monks is abductive, not deductive. Most of William's inferences are in fact abductive. But (II), as we shall see, is not.

In order to explain the difference between Zadig's and William's equine abductions, DelFattore has made appeal to the conception of "creative abduction":

[W] hile Zadig's description of the king's horse is confined to what the physical evidence suggests, William's description of the abbot's horse includes a creative abduction based on his knowledge of how various authorities describe the ideal horse and on his belief that monks rely more heavily on authority than on the evidence of their own senses. Thus William states that the horse has a small head, 
large eyes, and pointed ears - not because he has found physical evidence to suggest that the horse has these qualities but because he invents a horse based on what he guesses the monks believe about it. (DelFattore 1988: 131) ${ }^{8}$ surprising fact concerning the monks' belief that those horses are beautiful which possess a small head, sharp ears, and big eyes? That the monks so believe (on good authority) is not a fact that demands explanation, but the rule that is in William's possession, which he applies to something that would be explained by that rule, if the latter were true. As a rule, it is available in William's encyclopedia, and thus if (II) were abductive, the reasoning in question should rather qualify as undercoded, not creative abduction (contra DelFattore). Since the rule connects beauty and specific anatomical features, that which is explained by the rule should consequently be either that Brunellus is a fine horse (in fact, the finest of the abbey), or that he has certain features. But this latter cannot be the fact that demands explanation, for it is not something that William could have observed. Nor is in inferable from what he did observe. What he did observe is that the group includes the cellarer. From this, we have seen, he infers by (I) that the horse sought must be the finest of the abbey. This is the fact that falls under the rule. If we attempt to put (II) into a logical form, the result is the following:

(II) The monks believe that a fine horse must have a small head, sharp ears, and big eyes. The monks of the abbey believe that Brunellus is a fine horse.

Therefore, the monks believe that Brunellus has a small head, sharp ears, and big eyes.

is a clear example of syllogistic or deductive reasoning, as it applies a general rule to a case in order to obtain the result as conclusion. It may be said in weak sense to "explain" the case (second premise), in the sense that it makes it plain what that case involves. But the inference, so reconstructed, is deductive, not abductive (of either kind).

Is William performing a piece of deductive reasoning, then? In a sense, he is. But this piece of deductive reasoning is, precisely as in Peirce's three-stages model of scientific inquiry, the gateway between the hypothesis that forms the conclusion of a previous abduction and the testing of that hypothesis by means of the testing of its deductive consequences. William is not merely deducing the consequences of an idea arrived at by means of abduction. He is deducing the consequences of that idea in order to put that idea to experimental test. Once the necessary consequences of the hypothesis are drawn, William - just like the Peircean scientist - has to make an experiment to verify that hypothesis.

33 In the case of Brunellus, the experiment consists in enriching the description of Brunellus, which he has obtained by abductive reasoning from facts (the observed signs on the path) with characters which are not abduced from observed facts, but which are rather deduced from the conclusion of a previous abductive reasoning (conclusion of I). 
In so doing, William pretends to be performing an abductive reasoning from observed facts, while he is actually testing one of the hypotheses suggested by a previous abduction. The "amazement" with which the cellarer and the monks look at William after he describes Brunellus so accurately is the result of the test. It proves not that Brunellus really has a small head, sharp ears, and big eyes, but only that the monks so believe. And in fact William is careful to point out to Adso that the hypothesis to be tested does not concern the real horse, but only the monks' idea of it: "I am not sure he has those features, but no doubt the monks firmly believe he does." By adding to his description of the horse characters that he could not have abduced from observed facts, William proves that the hypothesis suggested by abduction - that the horse is the finest of the abbey - is a correct one. If it were not, the cellarer could have objected that, though William's description of Brunellus is correct as far as color, height, gallop, etc. are concerned, yet it is flawed in respect to size of the head and eyes and shape of the ears. The fact that the cellarer is "amazed" at William's accurate description is the inductive test of the validity of a hypothesis entertained on completely different grounds (i.e., on the ground that only the finest horse of the abbey would prompt the cellarer in person to take part on the chase).

The testing of the hypothesis is inductive in the authentic Peircean sense. The characters that William mentions in his description of Brunellus (small head, sharp ears, big eyes) are a sample of all the characters that Isidore (and, following his authority, the monks) believe a fine horse should possess (small head, sharp ears, big eyes, flaring nostrils, erect neck, thick mane and tail, round and solid hoofs). William may therefore be said to make the inductive generalization that what is found true of the predictions actually put to test (by including in his description of Brunellus a sample of the characters available in the encyclopedia) would be found true of all of them. Recall Peirce's characterization of induction quoted above: "induction is an argument which starts out from a hypothesis, resulting from a previous abduction, and from virtual predictions, drawn by deduction, of the results of possible experiments, concludes that the hypothesis is true, in the measure in which these predictions are verified." (CP 2.96). The inductive generalization performed by William consists in starting from a hypothesis resulting from a previous abduction (I), and from virtual predictions, drawn by deduction, of the results of possible experiments (II), concludes that the hypothesis is true in the measure in which those predictions are verified (the monks' assent to the conclusion of II).

"Books [Isidore's included] are not made to be believed, but to be subjected to inquiry." (NR 316). Abduction is for the sake of inductive verification. This is true also of the first, observation-laden abductions that William makes on the basis of the signs found on the path. When the monks and the servants reappear at the turn of the path leading the horse by its halter, William can verify his hypotheses as to the color, height, gallop etc. of the animal by looking at the animal itself; verification in this case simply consists in the direct perception of the horse. William is very clear about this point: "my intellect's hunger was sated only when I saw the single horse that the monks were leading by the halter. Only then did I truly know that my previous reasoning had brought me close to the truth." (NR 28). But while he can verify color, height, gallop, etc., he cannot verify the size of the head and eyes and the shape of the ears of the animal by direct perception, because that hypothesis does not concern the real features of the real animal, but only what the monks believe the animal's features to be. And while the former hypotheses are verified 
by the direct perception of the horse, the latter cannot be so verified, and can only be verified by deducing predictions from it and putting those predictions to test by including them into the description of the animal that is offered to the astonished cellarer.

In the overture of The Name of the Rose, Eco gives us a splendid sketch not simply of the abductive mode of reasoning, but of the entire, three-fold process of scientific inquiry that Peirce has theorized in his later writings. In Peircean terms, William's method is hypothetical-deductive in the sense that his hypotheses are first suggested by abduction, then developed by deduction, and finally verified by induction. The Zadig episode can hardly be said to be modeled on the Peircean, three-fold analysis of inquiry, because in this episode the only verification is the verification of the horse hypothesis, but nothing is deduced from the hypothesis to be subjected to inductive verification. Zadig does nothing in particular to verify his horse hypothesis. In this respect, while Zadig's horse abduction seems to be fashioned on Peirce's early analysis of abduction (the data are signs, and particularly indices that form an icon, of the conclusion), William's course of reasoning is more akin to Peirce's mature analysis of abduction (an hypothesis is suggested by abduction from data, and is subsequently analyzed by deduction and verified by induction).

\section{Meta-Abduction and the "Bottom Question of Logical Critics"}

\section{justification of the abductive mode of reasoning, although it may furnish an insight as to} the elements that may enter into some such argument.

looking retrospectively to his fortunate Brunellus hypothesis, he says to Adso:

in the case of the horse Brunellus, when I saw the clues I guessed many complementary and contradictory hypotheses: it could be a runaway horse, it could be that the abbot had ridden down the slope on that fine horse, it could be that one horse, Brunellus, had left the tracks in the snow and another horse, Favellus, the day before, the traces of mane in the bush, and the branches could have been broken by some men. I didn't know which hypothesis was right until I saw the cellarer and the servants anxiously searching. Then I understood that the Brunellus hypothesis was the only right one, and I tried to prove it true, addressing the monks as I did. I won, but I might also have lost. The others believed me wise because I won, but they didn't know the many instances in which I have been foolish because I lost, and they didn't know that a few seconds before winning I wasn't sure I wouldn't lose. (NR 305)

The Brunellus hypothesis was correct, but it could have been wrong. Abduction is fallible:

"I work on things of nature. And in the investigation we are carrying out, I don't want to know who is good or who is wicked, but who was in the scriptorium last night, who took the eyeglasses, who left traces of a body dragging another body in the snow, and where Berengar is. These are facts. Afterward I'll try to connect them - if it's possible, for it's difficult to say what effect is produced by what cause. An angel's intervention would suffice to change everything, so it isn't surprising that one thing cannot be proved to be the cause of another thing. Even if one must always try, as I am doing." "Yours is a difficult life," I said. "But I found Brunellus," 
William cried, recalling the horse episode of two days before. "Then there is an order in the world!" I cried, triumphant. "Then there is a bit of order in this poor head of mine," William answered. (NR 207)

"Horns." After having presented his three kinds of abduction (overcoded, undercoded, and creative), Eco adds a fourth kind, which he labels "meta-abduction." Meta-abduction "consists in deciding as to whether the possible universe outlined by our first-level abductions is the same as the universe of our experience" (H 207), i.e., whether the "order in the head" (world as represented) is the same as the "order in the world" (world as is independently of being represented). Eco explains his notion of meta-abduction through the Zadig example. Zadig "does not possess the scientific certainty that his textual hypothesis is true: it is only textually verisimilar. Zadig pronounces, so to speak, a teleological judgment. He decides to interpret the data he had assembled as if they were harmoniously interrelated." (H 213; original emphasis). Zadig does not know that his hypothesis (that the king's horse is such-and-such) is true. He only acts as if it were true.

Paolucci (2017a; 2017b) has convincingly argued that Eco's solution is at bottom Kantian: the abductive reasoner acts as if the representation of the world yielded by abductive reasoning were isomorphic to the world itself. Abductive reasoning is in this sense governed by a regulative, not a constitutive principle. A constitutive judgment or principle is one that determines its object, while a regulative judgment or principle does not determine its object, but only determines the rule for the determination of the object. Thus, in mathematics an analogy or proportion is always constitutive, for once three terms are given, the fourth is given as well; in philosophy, by contrast, an analogy is merely regulative: once three terms are given, what is given is not the fourth term, but only the relation of the three terms to the fourth, that is, what is given is only the rule to find that fourth term in experience (A179-180/B222-223). Thus, the synthetic a priori "mathematical" principles of pure understanding are constitutive, while the synthetic a priori "dynamical" principles are merely regulative. A constitutive proposition describes the world. A regulative proposition prescribes what we ought to think about the world (A509/B537).

43 According to Eco, the leading principle of abduction, and thus its justification, is regulative, not constitutive. If it were constitutive, any abductive representation of the world would ipso facto be true, i.e., would perfectly correspond to the world. But nothing guarantees that the world is isomorphic to the representation of it: in abduction we merely act as if our representations were isomorphic to the world, without however 
thereby asserting that the world is in fact as it is represented to be. This is the metaabduction that underlies every possible abduction: we reason abductively as if abduction were a valid form of reasoning, and thus we proceed upon the meta-abduction that the world represented in our first-level abductions is the same as the world of our experience.

The notion of meta-abduction is Eco's Kantian solution to the problem of the justification of abduction. As such, it precisely corresponds to Peirce's, as we shall now see. According to the late Peirce, the question of the justification of the several kinds of reasoning is a problem of "logical critics" (the central, and fundamental, department of logic, which follows speculative grammar and precedes methodeutic, cf. R 478, 1903). The justification of deduction is not, properly speaking, a problem of logic (RL 75: 12-3, 1902). All deductive reasoning is mathematical reasoning, and mathematical reasoning for Peirce is not subject to logic (CP 2.191). A piece of deductive reasoning is mathematically valid before being logically valid. Deductive logic depends on mathematics; it is in fact applied mathematics, i.e., mathematics applied to logic (CP 4.228, 4.233, 4.240, 1902). Deduction is valid because it is mathematically valid.

Induction is valid because it is auto-corrective. Though any single induction may go wrong, yet inductive reasoning - reasoning from a sample to the whole - pursues a method whose continual and repeated application will yield correct representations more often than wrong, and therefore will in the long run approximate complete truth. For Peirce that is real which is represented in a true representation, and truth depends not on this or that representation but only on the representation that will be yielded in the long run by scientific (i.e., inductive and abductive) investigation, and which is therefore independent of particular and individual representations. The justification of induction as that of abduction, as we shall see - assumes the reality hypothesis, i.e., that there is a way things are, independent of the representation. But how things are depends on how we will be led to represent them (if investigation is protracted far enough), because the real is nothing more than the object of a true representation. ${ }^{9}$

The problem of the justification of abduction is "the bottom question of logical Critic" (EP2: 443, 1908). Peirce's solution to the bottom question of logical critics is the following:

The logical justification of Retroduction [...] is as follows. In the first place, we certainly do thoroughly believe and cannot help so believing, do what we may, that some reasonings are sound. For we can free ourselves of a belief only by reasoning ourselves out of it, and to do this is to believe that some reasonings are sound. Now although it is, of course, one thing to believe a proposition, no matter how thoroughly and firmly, and quite another for the proposition to be true, yet practically for the believer they are one and the same. For if his belief is perfect he thinks he is sure it is true and between that and his thinking it is true there is no practical difference. We must and do admit, therefore[,] that some reasonings are sound. But to say this is to say that some instinct or natural impulse to believe is in conformity with the real nature of things; and the only question is how far that conformity extends. This can only be ascertained by sampling; and the process of sampling will consist in taking Retroduction after Retroduction and testing the truth of each by as large a sample of its consequences as can conveniently be obtained. This justifies Retroduction, which simply puts that process of testing into practice for single Retroductions; and there is nothing in the justification that cannot be learned from indubitable external observation and equally indubitable reasoning. (R 637: 13-4, Oct. 1909) 

grounded upon the more fundamental abduction, which we may call ur-abduction, that nature is explainable. Let us attempt to spell out the details of his argument. The argument is based upon the premise that some reasoning is sound. This premise is something that we cannot doubt. For we actually have direct experience of sound inferences, and thus doubting that some reasoning is sound would amount to doubting something of which we have direct experience. According to Peirce, such a doubt would only be a feigned doubt. But though it is unscientific and unphilosophical to suppose that any particular fact will never be doubted, yet "we cannot go behind what we are unable to doubt" (W3: 14). In logic we must begin with some belief which is not subjected to doubt (though it may be doubted in the future), and mere pretense to doubt "can result in nothing but a show of demonstration of things really taken for granted" (W2: 189; cf. W2: 212). Thus, logic requires that we admit that some reasoning is sound.

But this admission amounts to the admission that, in some cases at least, we truly know things as they really are. This is nothing more than a hypothesis: the hypothesis that we truly have some power of knowing things, that we have a power of abduction. In Peirce's terms, the hypothesis is that we have "some instinct or natural impulse to believe [...] in conformity with the real nature of things." As another passage from Peirce's 1908 "Neglected Argument" recites, "[t]here is a reason, an interpretation, a logic, in the course of scientific advance; and this indisputably proves [...] that man's mind must have been attuned to the truth of things in order to discover what he has discovered. It is the very bed-rock of logical truth." (EP2: 444). The hypothesis that man has an instinct to truly represent reality is the fundamental hypothesis of scientific inquiry, "the bed-rock of logical truth."

this fundamental hypothesis, like every hypothesis, must be put to test to see whether and to what extent it is verified. Once the existence of sound reasoning, i.e., of reasoning by which we truly know reality, is admitted, the only question that remains to be settled is how far that knowledge extends, i.e., how far the hypothesis can be verified ("the only question is how far that conformity extends"). Now, as we know from previous discussion, a question concerning the truth of a hypothesis can only be answered by induction. Therefore, the extent to which we have a power of truly knowing real things by abductive reasoning is determined by checking how far our abductions are successful or have been successful in the past. And since the history of science provides us with abundant examples of successful abductive inferences, the fundamental abduction or urabduction that we have a power of abduction is verified, at least in some measure, by the history of science: "since all modern science depends ultimately on this method, its history furnishes such a sample of intelligent hypotheses, that a student of that history must be blind not to see that man's mind has a certain power of divining the truth." ( $\mathrm{R}$ 638: 14-5). The history of science is as it were the ur-induction that verifies the urabduction that we have a power of abduction, just like single inductions verify single abductions ("simply puts that process of testing into practice for single Retroductions").

For Peirce the justification of abductive reasoning lies in the fundamental hypothesis, or ur-hypothesis, that we have a power of truly knowing things by means of abductive reasoning. As with every hypothesis, this ur-hypothesis must be verified, and is verified through an argument from the history of science (ur-induction). Abduction is therefore directly justified through an ur-abduction, which in its turn is verified inductively: the justification of abduction is for Peirce directly abductive, and indirectly inductive.

European Journal of Pragmatism and American Philosophy, X-1 | 2018 
51 It should now be clear to the reader that what I call Peirce's ur-abduction is precisely Eco's meta-abduction. As the latter consists in the abduction that that the world represented in our first-level abductions is the same as the world of our experience, so the former consists in the ur-abduction that our abductions are sound. In both cases, the justification consists in admitting a regulative, not a constitutive principle of reasoning. As for Eco the abductive reasoner acts as if the representation of the world yielded by abductive reasoning were isomorphic to the world itself (meta-abduction), so for Peirce the abductive reasoner acts as if the ur-abduction that we can truly know real things were a sound one.

52 According to Paolucci, there is a fundamental difference between Peirce's and Eco's theories: while for Peirce there is continuity (synechism) between mind and matter, between thought and world, for Eco no such continuity is possible; for Eco "there is nothing as the structure of the real that allows us to choose one interpretation rather than another [...] The power of falsehood is not the lume naturale and the constitutive principle of synechisim is invalidated on a semiotic level." (Paolucci 2017a: 263; original emphasis). For Eco, that which for Peirce is a "constitutive" principle of logic is only "regulative": "although we know that the order of the world does not necessarily correspond to that of thought, we must proceed as if this correspondence existed. [...] This then is a synechism that is not constitutive (as in Peirce) but only regulative of our inferences and interpretations." (2017a: 270-1; original emphasis). ${ }^{11}$ According to Paolucci, it is not within the domain of Eco's theory that the constitutive continuity between representation and world represented is to be found, but only within the distinct and yet related domain of narrative: "Eco is prepared to allow this synechistic order only in those world-models constructed by 'narrative' and not in the real world: novels contain things that do not exist in the world, that is to say, a certain correspondence between the conjectures of interpretation and the world-model." (2017a: 267; cf. also 2017b, ch. 10). ${ }^{12}$

53 As far as Eco's theory of abduction is concerned, Paolucci's argument is certainly persuasive and revealing. However, I would tend to see the distance between Eco and Peirce on matters abductive as less pronounced than Paolucci seems to think. The crux of the matter concerns, as I believe I have shown, not the analysis of abductive reasoning but the nature of the philosophical justification of it. If Peirce's solution to the "bottom question of logical critics" consisted in the stipulation of a constitutive principle of abductive soundness, then Eco's position would really differ from Peirce's. But as I have argued above, Peirce's justification of abduction is directly abductive (and, therefore, indirectly inductive), for it is directly based on the ur-hypothesis or ur-abduction that our abductions are sound, and indirectly on the inductive verification of such ur-abduction through an argument from the history of science (ur-induction). This, far from being an affirmation of the constitutive nature of abduction's principle, is rather a clear statement that that principle is merely regulative. If the validity of abduction were grounded by Peirce on some form of deductive reasoning, we would be justified in holding that such a justification would make the principle of abduction constitutive. For in that case, the world would necessarily (i.e., deductively) be as we would represent it to be. This is not Peirce's idea of the justification of abduction. For him abduction is valid because it "is the result of a method that must lead to the truth if [...] it is possible to attain the truth. Namely we must assume the human mind has a power of divining the truth, since if not it is hopeless even [to reason]." (R 276: 39, 1910). We must "assume" that reality can truly be 
known by abductive reasoning, that is, we must assume the fundamental hypothesis, or ur-hypothesis, that our abductions are sound. Just as for Eco, for Peirce although we know that the order of the world does not necessarily (i.e., deductively) correspond to that of thought, we must proceed as if (i.e., on the hypothesis that) this correspondence existed.

Paolucci rightly emphasizes the fact that for Peirce the existence of an epistemological isomorphism between the order of representations and the order of things is only a special case of the metaphysical isomorphism between mind and matter, which Peirce had illustrated in the 1890-1892 Monist "metaphysical project" (W8: 84-205) in the context of an exposition of his "synechistic metaphysics." Now, synechism is for Peirce a regulative, not a constitutive, principle of logic: "a regulative principle of logic requires us to hold each thing as continuous until it is proved to be discontinuous" (R 398: 11, 1894, emphasis added); "Synechism is not an ultimate and absolute metaphysical doctrine; it is a regulative principle of logic, prescribing what sort of hypothesis is fit to be entertained" (CP 6.173, 1902, emphasis added). Hypotheses are fit to be entertained which involve continuity rather than discontinuity (CP 6.169), and therefore since "the synechist maintains that the only possible justification for so much as entertaining a hypothesis is that it affords an explanation of the phenomena" (CP 6.171), the fact that many of our abductions have been successful has to be explained by the synechistic hypothesis that world and thought are continuous with each other. But this synechistic hypothesis is, indeed, a hypothesis, not a fact: it does not make world and thought continuous with each other, but prescribes how to proceed in our scientific investigations: we must proceed on the assumption that things are continuous rather than discontinuous, that world and thought are continuous with each other, and thus that our thoughts can really grasp how the world really is. ${ }^{13}$

He is most clear about this in a draft of the third Lowell Lecture of 1903:

Kant has a famous distinction between constitutive principles and regulative principles. A constitutive principle express[es] what is so, whatever that may mean. A regulative principle expresses how you must think about a matter in order to attain your purposes, whether it be so, or not. For example, in a hand of whist, when only three rounds remain to be played and you have the lead, you must think of the cards as lying so that it will be possible for you to win the odd trick, although you have no evidence that it is so. ( $\mathrm{R}$ 462: 40,1903; original emphasis)

In any game of cards there is an element of abduction. Namely, the player has to make the hypothesis that a certain configuration of cards is in the other players' hands or covered on the table. The player does not know what the configuration of the cards is, but must play as if that configuration were known. Abduction is grounded on a regulative principle of logic.

If Peirce's synechism were an ultimate and absolute metaphysical doctrine, for example the doctrine that mind and matter are continuous with one another, then we would be justified to hold that Peirce's justification of abductive reasoning amounts to a constitutive form of synechism. But Peirce is very clear that his synechism is a regulative, not a constitutive, principle of logic, which merely prescribes to act as if matter and mind were continuous with one another, and therefore, in abductive reasoning, as if our abductions were sound. 


\section{BIBLIOGRAPHY}

BELlUCCI Francesco, (2017), Peirce's Speculative Grammar. Logic as Semiotics, New York \& London, Routledge.

Bondanella Peter, (1997), Umberto Eco and the Open Text, Cambridge, Cambridge University Press. coHEN Michael, (1988), “The Hounding of Baskerville: Allusion and Apocalypse in Eco's The Name of the Rose," in M. Thomas Inge (ed.), Naming the Rose. Essays on Eco's The Name of the Rose, Jackson, Mississippi, University Press of Mississippi.

CONAN DOYLE Sir Arthur I., (1887), A Study in Scarlet, London, Ward Lock \& Co.

DELfATtore Joan, (1988), "Eco's Conflation of Theology and Detection in The Name of the Rose," in M. Thomas Inge (ed.), Naming the Rose. Essays on Eco's The Name of the Rose, Jackson, Mississippi, University Press of Mississippi.

ECo Umberto, (1976), A Theory of Semiotics, Bloomington, Indiana University Press (T).

ECo Umberto, (1979), Lector in fabula, Milan, Bompiani (LF).

ECo Umberto, (1980), The Name of the Rose, trans. by W. Weaver, St. Diego, Harcourt (or ed. Milan, Bompiani) (NR).

ECO Umberto, (1983), "Horns, Hooves, and Insteps. Some Hypotheses on Three Types of Abduction," in Umberto Eco \& Thomas A. Sebeok (eds), The Sign of Three, Bloomington, Indiana University Press (H).

FANN K. T., (1970), Peirce's Theory of Abduction, The Hague, Nijhoff.

GINZBURG Carlo, (1983), "Morelli, Freud, and Sherlock Holmes: Clues and Scientific Method," in Umberto Eco \& Thomas A. Sebeok (eds) The Sign of Three, Bloomington, Indiana University Press. GOUDGE Thomas A., (1940), "Peirce's Treatment of Induction," Philosophy of Science, 7 (1), 56-8. KRUIJFF Geert-Jan, (2005), “Peirce's Late Theory of Abduction: A Comprehensive Account," Semiotica, 153, 431-54.

NIINILUOTO Ilkka, (1999), “Defending Abduction,” Philosophy of Science, 66 (Supplement), 436-51. PAOLuCCI Claudio, (2010), Strutturalismo e interpretazione, Milan, Bompiani.

PAOLucci Claudio, (2017a), “Eco, Peirce, and the Anxiety of Influence: the Most 'Kantian' of Thinkers," in Sara C. Beardsworth \& Randall E. Auxier (eds), The Philosophy of Umberto Eco, Chicago, Open Court, 251-77.

PAOLUCCI Claudio, (2017b), Umberto Eco, Milan, Feltrinelli.

PEIRCE Charles S., (1787-1951), A Harvard manuscript (Charles S. Peirce Papers, MS Am 1632, Houghton Library, Harvard University) as listed in Richard Robin, Annotated Catalogue of the Papers of Charles S. Peirce (Amherst, University of Massachusetts Press, 1967) (R); (RL) refers to letters that are listed in the correspondence section of Robin's catalogue.

PEIRCE Charles S., (1932-1958), Collected Papers of Charles Sanders Peirce, 8 vols, edited by

C. Hartshorne, P. Weiss, and A. Burks, Cambridge, Harvard University Press (CP). 
PEIRCE Charles S., (1982-2009), Writings of Charles S. Peirce: A Chronological Edition, 7 vols, edited by. E. Moore, C. J. W. Kloesel et al., Bloomington, Indiana University Press (W).

PEIRCE Charles S., (1998), The Essential Peirce, vol. 2, edited by the Peirce Edition Project, Bloomington, Indiana University Press (EP2).

PIETARINEN Ahti-Veikko \& Minghui MA, (2016), “A Dynamic Approach to Interrogative Construal of Abductive Logic," IfCoLog Journal of Logics and their Applications, 3 (1), 73-104.

REILLY Francis E., (1970), Charles Peirce's Theory of Scientific Method, New York, Fordham University Press.

SEBEOK Thomas A. \& Jean UMIKER-SEBEOK, (1983), “'You Know My Method': A Juxtaposition of Charles S. Peirce and Sherlock Holmes," in Umberto Eco \& Thomas A. Sebeok (eds), The Sign of Three, Bloomington, Indiana University Press.

SHORT Thomas L., (2010), “What Was Peirce’s Objective Idealism?,” Cognitio, 11 (2), 333-46.

TIERCELIN Claudine, (1998), “Peirce's Objective Idealism: A Defense," Transactions of the Charles S.

Peirce Society, 34 (1), 1-28.

TRUZZI Marcello, (1983), “Sherlock Holmes: Applied Social Psychologist," in Umberto Eco \& Thomas A. Sebeok (eds), The Sign of Three, Bloomington, Indiana University Press.

voltAire, (1910), Zadig, And Other Tales, trans. by R. B. Boswell, London, Bell and Sons.

\section{NOTES}

1. In its turn, the model of the horse episode in Zadig was the ancient oriental tale of three brothers who "abduce" the exterior aspect of a camel without having seen it. The tale was included in the xvith century collection Peregrinaggio di tre giovani figliuoli del re di Serendippo (Venice 1557, translated from Persian into Italian by Christopher the Armenian); see Ginzburg (1983: 124-6).

2. On Peirce's early, semiotically-oriented analysis of abduction see Bellucci (2017, ch. 1).

3. See Fann (1970: 28). On the difference between Peirce's early and late theory of abduction see Paolucci (2010: 155-60); on the late theory see Kruijff 2005.

4. Cf. Reilly (1970: 62).

5. Cf. Niiniluoto, "the conclusion of abduction states that there are reasons for pursuing a hypothesis [...] or finding a hypothesis testworth" (1999: S441). On the "interrogative" model of abduction see Pietarinen \& Ma 2016. It has to be observed that the sequence abductiondeduction-induction reflects the categorial sequence firstness-secondness-thirdness. This ordering may have been influenced by the principle of categorial subdivisibility, according to which in any triadic subdivision into firsts, seconds, and thirds, there is one first, two seconds, and three thirds. Deduction, being second, has two sub-types (probable and necessary), and induction, being third, has three (crude, qualitative, quantitative). Thus he writes in the Logic Notebook: "If my present view, held for four or five years, is right that Abduction Deduction Induction [are] Primarian, Secundarian, and Tertian, then there ought to be two types of Deduction \& three of Induction." (R 339: 196r, 1901). However, the 1902 ordering corresponds to neither the 1867 ordering - in which induction was indexical and thus connected with the second category, while deduction was symbolic and thus connected with the third - nor to Peirce's later semiotic taxonomies - in which again induction is connected with the second category and deduction with the third; cf. R 339: 285r (1906). On Peirce's oscillations as regards the 
correspondence between the kinds of reasoning and the categories see Bellucci (2017: 206-11, 319-20).

6. In the Trattato, in the context of his theory of sign production, Eco considers imprints, symptoms, and clues as signs produced by means of "recognition": "In order to be considered as the functive of a sign-function the object or event must be considered as if it had been produced by ostension, replica or invention and correlated by a given kind of type/token-ratio." ( $\mathrm{T}$ § 3.6.2; original emphasis). In symptoms and clues the type/token-ratio is facilis (the expression-token is accorded to an expression-type according to a code), while in imprints the ratio is difficilis (the expression-token is directly accorded to its content, either because no expression-type exists or because the expression type is identical with content-type, cf. T § 3.4.9). In "Horns" this typology is used to explicate Zadig's inferential moves.

7. Cf. "An hour ago I could expect all horses, but not because of the vastness of my intellect, but because of the paucity of my deduction," NR 28 (emphasis added); cf. also NR 96, 209, 354.

8. See also Cohen (1988: 67), in the same volume.

9. The best work on Peirce's theory of induction remains Goudge 1940.

10. Cf. the following passage: "This kind of reasoning [abduction] is justified by two propositions taken together. One is that man's mind which is a natural product formed under the influences which have developed Nature (here understood as including all that is artificial,) has a natural tendency to think as Nature tends to be. This must be so if man is ever to attain any truth not directly given in perception; and that he is to attain some such truth he cannot consistently, nor at all, deny. The other proposition is that no other process of deriving one judgment from another can ever give any substantial addition to his knowledge; so that, if he is to reason at all, we must assume that this kind of reasoning succeeds often enough to make it worth while; since it certainly is not worth while to leave off reasoning altogether." (R 876: 3); cf. also R 905 (1908); R 841-3 (1908); R 328 (n. d.).

11. Although the name of the detective hero of The Name of the Rose (William of Baskerville) is a clear reference to the princeps nominalium (William of Ockham), it would be improper to ascribe to Eco a form of nominalism on the basis of his theory of the justification of abduction. As Paolucci has persuasively argued, Eco was by no means a nominalist, but a realist and a pragmatist of the Peircean stripe: the Latin sentence that closes The Name of the Rose ("stat rosa pristina nomine, nomina nuda tenemus") should not be taken as a profession of nominalism on Eco's part, but as Adso's puzzlement about the sense of the story that he has just narrated; see Paolucci (2017b: 156-9).

12. One is tempted to see a connection between Eco's idea of a "narrative consistency" of abductive reasoning and his semiotic theory of possible worlds. See LF, ch. 8.

13. It may be objected that Peirce's doctrine of "objective idealism," namely "that matter is effete mind, inveterate habits becoming physical laws" (CP 6.25), seems to imply that synechism is a constitutive and not a regulative principle. But Peirce is equally clear that this doctrine has the status of a hypothesis. Thus in a 1890 "Sketch a New Philosophy" he writes: "The only possible way of explaining the connection of body and soul is to make matter effete mind, or mind which has become thoroughly under the dominion of habit, till consciousness and spontaneity are almost extinct." (W8: 22). The doctrine of objective idealism is an explanation, i.e. the explanation of why matter and mind, world and thought, are as connected as they appear to be. Qua explanation, this doctrine is a hypothesis, for the only manner of explaining anything is by means of abductive reasoning. And qua hypothesis, this doctrine constitutes a regulative principle. On Peirce's “objective idealism” see Tiercelin 1998 and Short 2010. 


\section{ABSTRACTS}

This paper argues that Umberto Eco had a sophisticated theory of abductive reasoning and that this theory is fundamentally akin to Peirce's both in the analysis and in the justification of this kind of reasoning. The first section expounds the essentials of Peirce's theory of abduction, and explains how Peirce moved from seeing abduction as a kind of reasoning to seeing it as a stage of the larger process of inquiry. The second section deals with one of Eco's paradigmatic examples of abduction, i.e., William of Baskerville's abduction concerning the horse Brunellus in the overture of The Name of the Rose, and shows that, just like in Peirce's three-stages model of inquiry, William's abductions are verified by means of deduction and induction. The third section examines the problem of the justification of abductive reasoning, and argues that both Peirce and Eco solved this problem through the idea that the justification of abduction is itself abductive (meta-abduction in Eco, ur-abduction in Peirce).

\section{AUTHOR}

\section{FRANCESCO BELLUCCI}

University of Bologna

francesco.bellucci4[at]unibo.it 